\title{
COMUNIDADES DE PRÁTICA COMO MEIO DE DESENVOLVIMENTO PROFISSIONAL DE GRUPOS EM SITUAÇÃO DE VULNERABILIDADE SOCIAL ${ }^{1}$
}

\author{
Gisele Hidalgo ${ }^{2}$ \\ Amarolinda Klein ${ }^{3}$
}

http://dx.doi.org/10.1590/1413-2311.163.61689

\begin{abstract}
RESUMO
A criação de vínculos sociais em meio digital pode colaborar para a aprendizagem, apoio mútuo e valores compartilhados em determinados grupos sociais. Este artigo apresenta os resultados de um estudo que buscou compreender como uma comunidade de prática criada na mídia social Facebook ${ }^{\circledR}$ pode ser utilizada para o desenvolvimento profissional de indivíduos que pertencem a grupos em situação de vulnerabilidade social. O método de pesquisa empregado foi a Design Science Research, por meio da qual se criou e testou um artefato - uma metodologia para a criação de uma comunidade de prática em mídia social (no Facebook®). A comunidade foi criada por um grupo de jovens com perfil sócio vulnerável que realizavam um curso técnico profissionalizante em uma unidade do SENAI. Os resultados do estudo apontam que o Facebook ${ }^{\circledR}$ possui as ferramentas necessárias para dar apoio à interação e aprendizagem em uma comunidade de prática, porém, outros fatores, como a ausência de lideranças, a necessidade do contato face a face e o uso de outras mídias (como aplicativos móveis) para interação, limitações na habilidade de escrita dos participantes e o narcisismo, comportamento característico no Facebook ${ }^{\circledR}$, entre outros, afetaram o nível de desenvolvimento da comunidade de prática criada nessa mídia.
\end{abstract}

Palavras-chaves: Comunidades de Prática. Mídia Social. Desenvolvimento Profissional. Vulnerabilidade Social. Facebook®.

\begin{abstract}
The creation of social ties in a digital environment can collaborate for learning, mutual support and shared values in social groups. This article presents the results of a study that aimed to understand how a community of practice based in the social media Facebook ${ }^{\circledR}$ can be used for the professional development of individuals who belong to groups in situation of social vulnerability. The research method employed was the design science research, used to create and test an artifact - a methodology for the creation of a community of practice in Facebook®. The community was created by a group of young students enrolled in a technical course in a unit of SENAI who have social vulnerability. The study results show that Facebook ${ }^{\circledR}$ has the tools required to support the interaction and learning in a community of practice, however, other factors, such as the lack of leadership, need of face to face contact and the use of other media (such as mobile apps) for interaction, the limitations of writing
\end{abstract}

\footnotetext{
${ }^{1}$ Recebido em 18/01/2016; aprovado em 26/05/2017.

${ }^{2}$ Universidade do Vale do Rio dos Sinos - giselehidalgo29@gmail.com.

${ }^{3}$ Universidade do Vale do Rio dos Sinos - amaroklein@gmail.com.

REAd | Porto Alegre - Vol. 23 - No Especial - Dezembro 2017 - p. 93-125
} 
skills by the participants and narcissism, a characteristic behavior in Facebook $®$, among other factors, affected the level of development of the community of practice created in that media.

Keywords: Communities of Practice. Social Media. Professional Development. Social Vulnerability; Facebook®.

\section{RESUMEN}

La creación de vínculos sociales en los medios digitales puede contribuir para el aprendizaje, la ayuda mutua y valores compartidos em ciertos grupos sociales. Este artículo presenta los resultados de un estudio que pretendió averiguar cómo una comunidad de práctica creada em los medios de comunicación social como el Facebook® puede ser utilizada para el desarrollo profesional de los individuos que pertenecen a grupos sociales vulnerables. El método de investigación empleado es Design Science Research, que ha creado y probado un artefacto, una metodología para la creación de una comunidad de práctica en los medios sociales (Facebook®). La comunidad fue fundada por un grupo de jóvenes con perfil socio vulnerable que realizaba un curso de capacitación técnica en una unidad del SENAI. Los resultados del estudio indican que el Facebook® tiene herramientas necesarias para apoyar la interacción y el aprendizaje en una comunidad de práctica. Sin embargo, otros factores, como la ausencia de liderazgo, la necesidad de contacto personal y el uso de otros medios (aplicaciones móviles) para interactuar, limitaciones em la capacidad de escribir de los participantes y el narcisismo, comportamiento característico en Facebook®, entre otros factores, afectan el nivel de desarrollo de la comunidad de práctica creada por este medio.

Palabras Clave: Comunidades de Práctica. Medios de Comunicación Social. Desarrollo Profesional. Vulnerabilidad Social. Facebook®.

\section{INTRODUÇÃO}

O mundo do trabalho globalizado e a economia do conhecimento instituem desafios constantes ao desenvolvimento social por estabelecerem diferentes estruturas locais de acesso aos fluxos de bens, informação, capital e conhecimento. Num contexto de pobreza e desigualdade, o conceito de vulnerabilidade social pode ser compreendido como um processo de exclusão, de discriminação ou de enfraquecimento de grupos sociais. Essa vulnerabilidade relaciona-se inversamente com a capacidade de tais grupos reagirem a desafios e enfrentarem as dificuldades inerentes ao viver (PALMA; MATTOS, 2001).

Neste cenário, verificam-se esforços, tanto do poder público como das organizações da sociedade civil e da iniciativa privada, que se traduzem em programas e projetos de qualificação profissional como forma de acesso ao emprego, ao empreendedorismo e, consequentemente, à renda. A aprendizagem profissional está diretamente ligada à inserção produtiva e à mudança de realidade social.

Segundo Oliveira (2004), na medida em que ocorre a dinamização e o avanço REAd | Porto Alegre - Vol. 23 - No Especial - Dezembro 2017 - p. 93-125 
tecnológico, gerencial e operacional do processo produtivo, são demandadas novas habilidades e qualificações profissionais mais complexas, com maior grau de escolaridade. Por isso, compreende-se a inclusão como subordinada e regida pelas competências demandadas pela dinamização das relações de produção das cadeias produtivas. Sempre que tais competências não conseguem ser atendidas, tende a se estabelecer a precarização da inclusão profissional nos elos frágeis das cadeias produtivas e nos setores menos dinâmicos da economia.

Também como parte desse contexto, atualmente as redes sociais não são somente uma simples tecnologia de transmissão de dados, mas são o núcleo de muitas áreas da atividade social, econômica e política. De acordo com Castells (2004), o século XX provocou a fusão de três processos independentes: exigências econômicas, demandas sociais por liberdade e comunicação, e avanços da tecnologia. As transformações advindas dessa união possibilitaram a criação de uma nova estrutura social, baseada nas redes, que inclui o rápido avanço e evolução de comunidades virtuais e a adesão em massa de diferentes camadas da população, especialmente adolescentes e jovens adultos.

A interação exerce um papel protagonista nas relações sociais, o que, no caso das redes sociais online, agrega valor ao processo de ensino e aprendizagem, processo este capaz de transformar realidades. Souza e Schneider (2012) destacam que essa transformação acontece tanto pela grande adesão de indivíduos, principalmente jovens, quanto pela quebra das barreiras geográficas e sociais que o ciberespaço favorece. A interação mediada pelo computador oportuniza as relações sociais e estas, geram laços sociais. Dentro desta lógica, o ser humano é visto como um ser de comunidade, de relações com seus semelhantes, relações estas que se destinam a buscar aquilo que o emancipe perante a sociedade (CHANLAT, 2000).

$\mathrm{O}$ ato de estabelecer vínculos sociais através de meio digital pode possibilitar a criação de ambientes comunitários virtuais em que os membros estabelecem laços de aprendizagem, apoio mútuo e valores compartilhados (DENG; TAVARES, 2013). Para Alle (2000), o aprendizado através de comunidades de prática virtuais é hoje um dos recursos mais poderosos. O conceito de comunidades de prática designa um grupo de pessoas que compartilham uma determinada prática e se unem por meio de um tópico ou interesse. Essas pessoas trabalham juntas para achar meios de melhorar o que fazem, ou seja, resolvendo problemas comuns na comunidade e aprendendo diariamente através da interação regular. A aprendizagem é vista como algo imbricado nas interações cotidianas e nas relações dinâmicas 
e de mútua influência entre pessoas e sistemas sociais dos quais participam, combinando transformação pessoal e mudanças nas estruturas sociais (WENGER, 2001).

Este estudo buscou compreender como as mídias sociais podem ser utilizadas para a aprendizagem e o desenvolvimento profissional de indivíduos que pertencem a grupos em situação de vulnerabilidade social. Trata-se de uma pesquisa exploratória que desenvolveu, junto a um grupo específico (em situação de vulnerabilidade social e que busca qualificação profissional), uma comunidade de prática no Facebook®. Esta pesquisa visou aliar a tecnologia da informação à construção de condições emancipatórias ao homem, o que para Freire (1996) vincula-se ao desenvolvimento individual de práticas autônomas e libertadoras. Assim como Gaiger (2004), que defende que somente por meio da criação de vínculos sociais e ajuda mútua é que se encontram elementos necessários para a superação do individualismo e devolução do papel destinado ao homem: o de ser social e comunitário.

A escolha pela mídia social Facebook® está ligada ao seu alcance. Hoje é a mídia social dominante, sendo usada como sinônimo de termos como redes sociais ou redes sociais online. O estudo de Manca e Ranjerit (2013) identificou 23 artigos relevantes sobre o uso dessa ferramenta com fins pedagógicos. As conclusões apontam que os aprendizes nessa mídia percebem o aplicativo como adequado para a socialização, uma vez que ajuda a fortalecer relações interpessoais, além de ser eficaz para a aprendizagem informal, já que expõem questões não abrangidas em momentos formais de aprendizagem.

Com base nesses elementos, formulou-se a seguinte pergunta de pesquisa: Como uma comunidade de prática, desenvolvida em ambiente de mídia social, pode contribuir para o desenvolvimento profissional de um grupo em situação de vulnerabilidade social?

Dentro desta problemática, o grupo selecionado para o estudo foi composto por participantes de um programa de formação profissional promovido pelo SENAI (Serviço Nacional de Aprendizagem Industrial).

O estudo se mostra relevante por razões de ordem teórica e empírica. Do ponto de vista teórico, encontram-se poucos estudos, em particular no Brasil, a respeito do uso de comunidades de prática em mídia social como ferramenta de aprendizagem e desenvolvimento profissional, especialmente em grupos em situação de vulnerabilidade social $^{4}$. Do ponto de vista empírico, o desenvolvimento desta pesquisa se justifica a partir da importância de se analisar o potencial das mídias sociais, especificamente do Facebook®, para processos de aprendizagem profissional, explorando conceitos no campo das redes

\footnotetext{
${ }^{4}$ Em pesquisa realizada até o mês de abril de 2015, nas bases de dados EBSCO, ScienceDirect e ScIELO. REAd | Porto Alegre - Vol. 23 - No Especial - Dezembro 2017 - p. 93-125
} 
sociais online e equacionando as potencialidades que a rede social Facebook ${ }^{\circledR}$ pode evidenciar como uma plataforma para o desenvolvimento de comunidades de prática.

A pesquisa gerou conhecimento sobre as facilidades, oportunidades e problemas encontrados através do uso de comunidades de prática em mídia social para fins de qualificação profissional de grupos sócio vulneráveis. Ao entender o potencial do uso dessa tecnologia para a aprendizagem e formação profissional, os resultados encontrados (tanto as experiências exitosas quanto as dificuldades e limitações), poderão servir como base de apoio junto a outros grupos em condições semelhantes.

A temática do desenvolvimento profissional como processo de inserção sócio-produtiva é uma das questões centrais nos debates acadêmicos das ciências sociais e um desafio constante para as políticas públicas que visam promover o desenvolvimento social. A inclusão produtiva concretiza-se pelo emprego ou pelo empreendedorismo, mas remete a uma etapa anterior: a educação. $\mathrm{Na}$ medida em que ocorre a dinamização e o avanço tecnológico, gerencial e operacional do processo produtivo, são demandas novas habilidades e qualificações profissionais mais complexas, com maior grau de escolaridade. Esses mesmos avanços tecnológicos devem ser pensados a favor da geração de oportunidades para o desenvolvimento profissional e inserção sócio econômica de grupos vulneráveis.

Após esta seção introdutória, o artigo está estruturado em cinco partes principais: revisão de literatura, método de pesquisa, análise dos dados, discussão e considerações finais.

\section{REVISÃO DA LITERATURA}

\subsection{COMUNIDADES DE PRÁTICA}

O conceito de Comunidades de Prática (CoP) baseia-se no desenvolvimento da aprendizagem humana através das interações sociais. Os autores Lave e Wenger (1991) definem o termo comunidade de prática como um grupo de pessoas que compartilham uma preocupação, um conjunto de problemas ou uma paixão por uma determinada prática, e que aprofundam seu conhecimento e especialização nessas práticas pela interação numa base continuada.

A identificação do valor criado nas CoP se apresenta nas formas como as pessoas interagem, recorrem umas às outras para aprender e resolver problemas comuns (WENGER; TRAINER; DE LAAT, 2011; KIMBLE; HILDRETH, 2006). As CoP possuem três grandes 
dimensões sociais: domínio (identificação do indivíduo com o tema); comunidade (espaço propício para as interações entre os membros); e prática (trocas de experiências e construção de significados). Dentro destas dimensões, ao projetar uma comunidade de prática, Wenger (2001) destaca os elementos básicos para a sua consolidação, apresentados abaixo.

- Conectividade - relações de intermediação entre as pessoas que precisam de ajuda e as pessoas que podem oferecer ajuda, construir relacionamentos. A forma de conectar também é importante, tanto pessoalmente quanto através de ferramentas e mídias sociais.

- Eventos - a organização de eventos promove a união da comunidade. É a comunidade que irá decidir os tipos de eventos necessários para o seu desenvolvimento: informais, sessões de resolução de problemas, perguntas e respostas, etc.

- Liderança - comunidades de prática precisam ter lideranças internas que conduzam o grupo quando forem encontradas barreiras ao seu desenvolvimento.

- Membros - os membros de uma comunidade devem ter senso crítico, porém, respeitando a opinião individual dos participantes. Para que os recém-chegados se tornem membros plenos, deve-se garantir ajuda e apoio, mas sem perder o foco no propósito da comunidade.

- Projetos de aprendizagem - As atividades devem ser direcionadas para explorar conhecimento, encontrar lacunas, desenvolver projetos de aprendizagem envolvendo membros com conhecimentos de áreas diferentes, criar guias para iniciantes, etc.

- Artefatos - as comunidades de prática devem produzir seu próprio conjunto de artefatos: documentos, ferramentas, histórias, símbolos, sites, etc. Os artefatos são representações das práticas exercidas e devem ser usados como base no processo de evolução da comunidade.

A prática em comunidade sugere não somente uma relação com atividades específicas, como também o estabelecimento de laços sociais, e implica que os participantes busquem tornar-se membros reconhecidos na comunidade. Em alguns grupos, o indivíduo é membro do núcleo da comunidade, já em outros, está mais à margem dela. Nesse sentido, existem diferentes graus de participação ou engajamento em uma CoP, de acordo com Wenger et al. (2002) e sintetizados abaixo.

- Nível central - composto por pessoas que participam ativamente das discussões e debates nos fóruns públicos, assumindo projetos da comunidade, identificando assuntos para tratar e movimentando a agenda de aprendizado da comunidade. Este REAd | Porto Alegre - Vol. 23 - Nº Especial - Dezembro 2017 - p. 93-125 
grupo auxilia o coordenador e lidera a comunidade.

- Nível ativo - as pessoas deste grupo participam regularmente das atividades, porém sem a intensidade do grupo central.

- Nível periférico - composto pela grande maioria dos participantes, que usufruem das discussões e conhecimentos gerados pela $\mathrm{CoP}$ mas sem manifestarem-se publicamente.

Inicialmente, as pessoas muitas vezes têm de participar de comunidades e aprender na periferia. Conforme se tornam capacitadas podem se "mover para o centro" da comunidade em particular. Os aprendizes participam em comunidades, e a aprendizagem ocorre quando os novos membros começam a dominar as habilidades e demonstram atitudes nas quais se percebe claramente que a participação deles se tornou legítima (ANTONELLO et al., 2011).

Os processos de aprendizagem realizados nas $\mathrm{CoP}$ contribuem para o desenvolvimento profissional, pois utilizam metodologias que estimulam a participação de diferentes atores. Schlager e Fusco (2003) destacam que novas práticas e tecnologias são trazidas para a comunidade por seus líderes, recém-chegados ou externos, e são adotadas através do discurso e da prática de seus membros, o que, ao longo do tempo, leva os recém-chegados a terem acesso a profissionais, ferramentas de conhecimento e normas sociais, desenvolvendo diferentes aptidões por meio dessas interações.

A transformação pela aprendizagem através do desenvolvimento de autonomia ocorre fortemente em razão da troca de experiências e do convívio social que fortalece laços de apoio mútuo e leva à reflexão e crítica da realidade da qual os integrantes das $\mathrm{CoP}$ fazem parte. Esses são aspectos fundamentais para o desenvolvimento profissional, que será melhor explorado na próxima seção.

\subsection{DESENVOLVIMENTO PROFISSIONAL}

A formação profissional pode ser considerada como um processo organizado de educação no qual os indivíduos aprimoram seus conhecimentos, desenvolvem as suas capacidades e aperfeiçoam suas atitudes e comportamentos, ampliando suas qualificações

técnicas ou profissionais. É um processo permanente onde as pessoas se preparam para o exercício profissional esperado pelas organizações e pela própria sociedade (BURNHAM; FAGUNDES, 2005).

Já o desenvolvimento profissional alcançado através da participação em comunidades

$$
\text { REAd | Porto Alegre - Vol. } 23 \text { - No Especial - Dezembro } 2017 \text { - p. 93-125 }
$$


de prática estabelece uma ligação direta com outro enfoque conceitual, o de competências. Seguindo-se a escola francesa, representada por autores como Le Boterf (2003) e Zarifian (2001), que analisam a competência como sendo um processo dinâmico reconhecido por meio do resultado de uma ação eficaz. Trata-se, portanto, da noção da competência prática ou da competência em ação.

O argumento de Le Boterf (2003) é que as competências se manifestam no centro de uma situação complexa ou no âmbito de um evento crítico. A competência se expressa na ação, na atitude do ator de ir além do prescrito. É preciso saber transpor: saber envolver-se, saber aprender e aprender a aprender. O profissional deve saber utilizar em um novo ambiente os conhecimentos adquiridos em contextos distintos. Le Boterf (2003) enfatiza que, ao transpor barreiras, o profissional reconhece semelhanças nas estruturas dos problemas a tratar ou das situações nas quais deve interferir. Para o autor, saber não é possuir mas agir, assim não há competência senão em ato. Seguindo a mesma lógica, Zarifian (2001) conceitua competência como a tomada de iniciativa e responsabilidade do indivíduo em situações profissionais com as quais se defronta.

O desenvolvimento de competências por meio da ação possui uma ligação clara com a aprendizagem proporcionada através das CoP, pois, nelas, há troca de casos e experiências de trabalho e ação conjunta na resolução de problemas concretos, além do desenvolvimento de habilidades interpessoais. Todos esses fatores são importantes elementos relacionados ao desenvolvimento das competências dos profissionais (LE BOTERF, 2003).

Os autores Schlager e Fusco (2003) enfatizam que o desenvolvimento dos membros de uma CoP ocorre por meio de ações (diálogo, construção, pesquisa), voltadas para a realização de um objetivo. As atividades são mediadas pelas ferramentas (técnicas e conceituais) e outros artefatos que estão disponíveis para os sujeitos. Ocorrem em um contexto e são influenciadas por uma comunidade circundantee pela sua divisão de trabalho (atribuição de papéis e responsabilidades).

A aprendizagem profissional proporcionada pela participação em uma comunidade de prática pode ser relacionada à inserção produtiva e mudança de realidade social quando aplicada a grupos vulneráveis socialmente e que buscam novas formas de inclusão produtiva. Segundo Oliveira (2004) na medida em que ocorre a dinamização e o avanço tecnológico, gerencial e operacional do processo produtivo, demandam-se novas habilidades e qualificações profissionais mais complexas, com maior grau de escolaridade. Por isso, compreende-se a inclusão como subordinada e regida pelas competências demandadas pela 
dinamização das relações de produção nas cadeias produtivas.

Assim, a busca pelo desenvolvimento profissional pode ser vista como uma forma de superar as desigualdades sociais (desemprego, exclusão, marginalização) que ainda mantêm grandes contingentes populacionais em condições de pobreza relativa e absoluta, como será explorado na sequência.

\subsection{VULNERABILIDADE SOCIAL}

O conceito de desigualdade social está ligado à vulnerabilidade social, termo que, segundo Janczura (2012), pode ser definido como exposição a riscos e baixa capacidade material, simbólica e comportamental de famílias e pessoas para enfrentar e superar os desafios com que se defrontam. Para Santos (1999), o aspecto político da exclusão revela que seu maior problema é a ausência de cidadania, o que impede os excluídos de perceberem como as carências são impostas e as oportunidades obstruídas.

A busca pela emancipação social de grupos vulneráveis inicia no processo de empoderamento ou fortalecimento pessoal. Para Kleba e Wendausen (2009), o empoderamento pessoal possibilita a emancipação dos indivíduos, com aumento da autonomia e da liberdade. O nível grupal desencadeia respeito recíproco e apoio mútuo entre os membros do grupo, promovendo o sentimento de pertencimento, práticas solidárias e de reciprocidade. $\mathrm{O}$ empoderamento estrutural favorece e viabiliza o engajamento, a responsabilização conjunta e a participação social na perspectiva da cidadania.

Visando criar formas de apoio para dar aos indivíduos condições de empoderamento, Friedmann (1996) destaca que o empoderamento está assentado sobre uma tríade interligada, centrada no sujeito e na unidade doméstica, ligada a outras unidades, formando uma rede social de relações empoderadoras que, "devido ao reforço mútuo, tem um potencial extraordinário para a mudança social". Assim, elementos como a informação, conhecimento, participação em organizações comunitárias, além dos recursos financeiros, tornam maior a capacidade de estabelecer e alcançar objetivos. Nesse sentido, as CoP podem ter um papel crucial na criação e fortalecimento de laços sociais, no desenvolvimento dos indivíduos e dos grupos, no oferecimento de apoio e ajuda mútua para vencer os desafios que se apresentam (LAVE; WENGER, 1991).

Nesse mesmo sentido, Rocha (2000) enfatiza que a construção da emancipação se dá a partir da troca de experiências e do convívio em sociedade, comunicação e reconhecimento de 
símbolos, em um processo sistemático de formação intelectual e moral do indivíduo.

$\mathrm{O}$ ato de estabelecer vínculos sociais através de meio digital possibilita a criação de ambientes comunitários virtuais em que os membros estabelecem laços de aprendizagem, apoio mútuo e valores compartilhados (DENG; TAVARES, 2013). Para Alle (2000), aprender através de CoP digitais virtuais é hoje um dos recursos mais poderosos para desenvolvimento do conhecimento com foco na aprendizagem.

Dentro dessa lógica, um dos pressupostos desse trabalho é que a aprendizagem em uma coletividade (comunidades, redes ou grupos) realizada através das mídias sociais, possa ser um caminho alternativo para o desenvolvimento social e profissional de indivíduos que buscam a inclusão social e econômica. As mídias sociais podem oferecer uma série de ferramentas para apoio à aprendizagem e ao desenvolvimento das $\mathrm{CoP}$, conforme será explorado na próxima seção.

\subsection{MÍDIAS SOCIAIS}

Em seu estudo sobre mídias sociais, Kaplan e Haernlein (2010) explicam que a ideia de socializar conteúdos através da Internet surgiu no início dos anos 80 , quando foram criados os primeiros sistemas de discussões com possibilidade de troca de mensagens públicas. A partir daí estabeleceram-se diversas maneiras de compartilhamento de dados e interações virtuais. Mídias sociais podem ser definidas, atualmente, como um grupo de aplicações baseadas na Internet, construídas sobre ideologias e fundamentos tecnológicos da Web 2.0, que permitem a criação e publicação de conteúdos gerados pelos usuários.

Com relação à aprendizagem, as mídias sociais destacam-se pela função cognitiva e relacional que proporcionam aos usuários através de diálogos, partilha de recursos, desenvolvimento de habilidades de comunicação e também à possibilidade de misturar vida pessoal e profissional (fatores que facilitam a aprendizagem informal).

Em seu estudo sobre comunidades virtuais na internet Tucker (2012) explica que estes sistemas normalmente têm capacidades de atendimento de comunidades um pouco mais completas que os sistemas de grupo de discussão, pois focam na interação, porém frequentemente lhes faltam repositórios sofisticados para documentos. A autora destaca as características típicas das comunidades virtuais: (a) identificação dos participantes, diretórios e perfis; (b) espaço para discussão assíncrona, bate-papo; (c) visualizador de presença, mensagens síncronas; (d) ferramentas de avaliação; (e) customização de espaço de REAd | Porto Alegre - Vol. 23 - No Especial - Dezembro 2017 - p. 93-125 
comunidade; (f) espaço para criação de subcomunidades; (g) calendário de eventos; (h) análise de atividade; (i) ferramentas de administração e criação de produtos.

A Figura 1 representa a ideia de como um grupo criado na mídia social Facebook® pode atender à definição de Wenger (2001) de CoP, como espaços para aprendizagem através da troca de experiências e as características apontadas por Tucker (2012), com as ferramentas disponíveis no Facebook® para a criação de grupos virtuais.

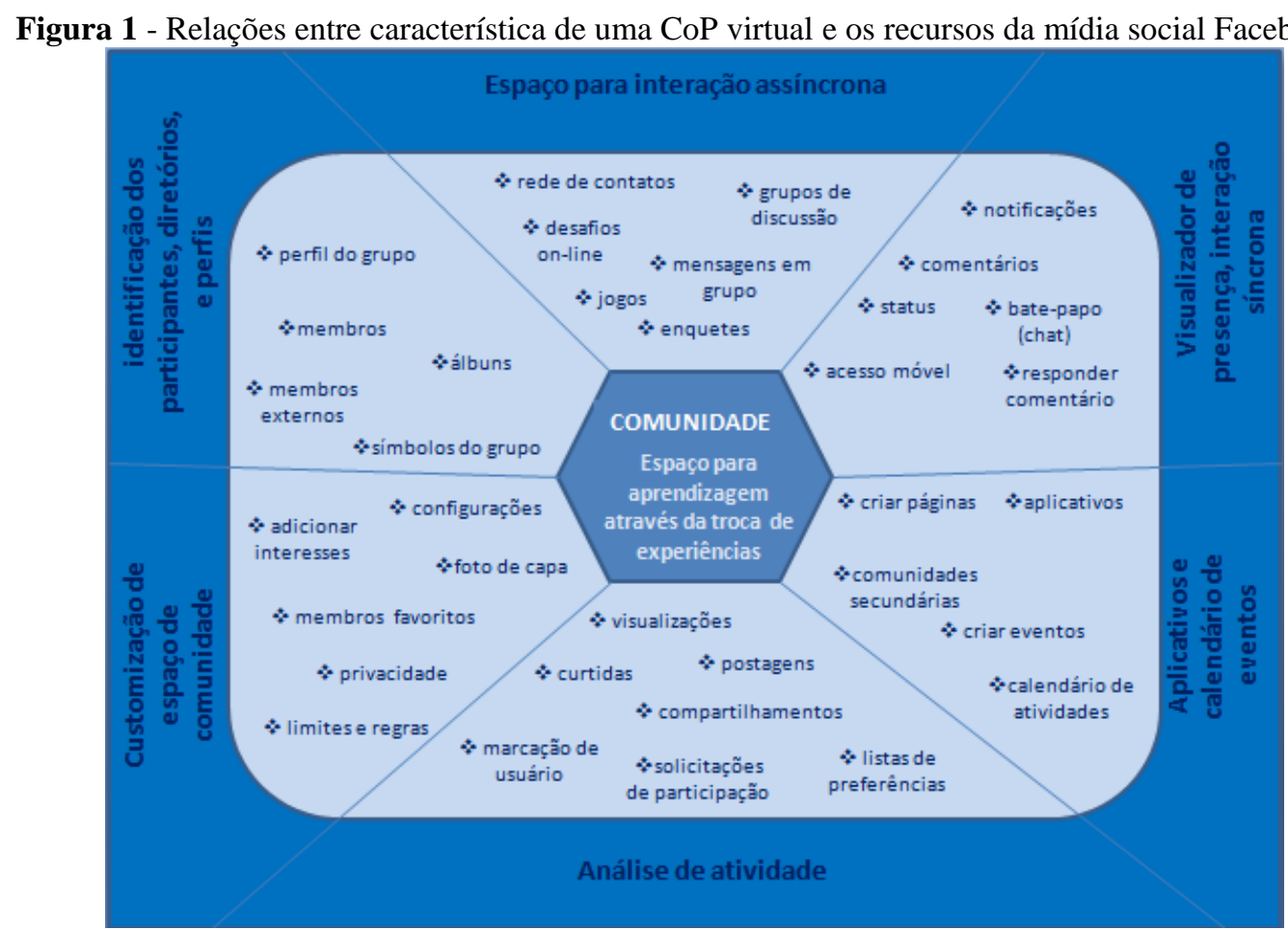

Fonte: elaborado pelas autoras com base em Wenger (2001) e Tucker (2012).

A Figura 1 fornece uma visão das possibilidades de uso dos recursos do Facebook ${ }^{\circledR}$ que apoiam a interação e troca de conhecimento com relação às principais categorias encontradas em CoP virtuais. De uma maneira geral percebe-se que um grupo em mídia social digital pode constituir, nessa mídia, um espaço relativamente informal que permite aos usuários exercerem os seus próprios pensamentos, reflexões, críticas e fazer suas próprias conexões.

Apoiado nesta ideia, este estudo buscou aliar a tecnologia da informação, por meio das mídias sociais (que permitem comentários dos colegas e contextualização da aprendizagem,) à construção de condições emancipatórias do homem, tendo em vista o que, para Freire (1996), vincula-se ao desenvolvimento individual de práticas autônomas e libertadoras. Aprender dentro de uma CoP envolve participação nas atividades comunitárias para criar, 
compartilhar e construir em conjunto, o que desperta sentimentos de confiança, bem como uma sensação de presença e de mútuo apoio, o que é importante tanto para o desenvolvimento profissional quanto para a superação da vulnerabilidade social.

\section{MÉTODO}

O método utilizado neste trabalho foi a Design Science Research, que é um método de pesquisa que pressupõe a ação do pesquisador em uma determinada realidade, compreendendo, construindo e testando uma possível solução para um problema (FREITAS et al., 2015; DRESCH et al., 2015). Este método compreende as etapas (FREITAS et al., 2015; TAKEDA et al., 1990; VAISHNAVI; KUECHLER, 2004; MANSON, 2006) apresentadas na sequência.

(1) Entendimento ou Conscientização do Problema - Nesta etapa ocorre o entendimento de um problema para o se irá buscar uma solução.Nesta pesquisa, o entendimento iniciou com a seleção dos sujeitos de pesquisa, dentro dos critérios definidos pelo estudo (estudantes de cursos profissionalizantes com perfil sócio-vulnerável) e posterior uso de instrumentos de diagnóstico do seu perfil, hábitos de utilização de Tecnologias da Informação (TIC) e mídias sociais, bem como necessidades de formação profissional. Para isso, foram utilizadas as técnicas de grupo focal (dois grupos de foco foram realizados, com 8 alunos em cada um deles, pertencentes, respectivamente, às turmas do turno da manhã e da tarde do curso técnico), questionário (aplicado junto aos 43 potenciais participantes) e observação direta da dinâmica de interação dos grupos em aula (em torno de 30 horas de observação), que permitiram a compreensão do contexto social, de aprendizagem e tecnológico dos participantes, incluindo: necessidades de aprendizagem para sua formação profissional, perfil socioeconômico, demográfico e de uso de TIC, e formas de interação e comunicação já adotadas.

(2) Sugestões - a etapa de sugestão consistiu em planejar e delinear o artefato. O artefato construído foi um método para a criação de uma CoP na mídia social Facebook®. Assim, as sugestões para a concepção do formato de CoP digital foram estabelecidas em reuniões com o grupo de participantes. Primeiramente,realizou-se uma apresentação dos conceitos teóricos considerados pela pesquisa, que tratam das relações estabelecidas entre os recursos disponíveis na mídia social Facebook ${ }^{\circledR}$ e as características de uma CoP. Demonstrar essa relação foi fundamental para que os integrantes do grupo pudessem perceber as possíveis

REAd | Porto Alegre - Vol. 23 - No Especial - Dezembro 2017 - p. 93-125 
contribuições de uma CoP para o seu desenvolvimento profissional, e identificar como o Facebook ${ }^{\circledR}$ poderia apoiar o desenvolvimento da CoP que seria por eles criada.O método para criação da CoP (artefato) compreendeu os seguintes passos: (a) estabelecimento dos objetivos e propósitos do grupo; (b) definição dos modos de interação entre os participantes da comunidade; (c) definição de perfis e papéis dos integrantes na comunidade; (d) definição das formas de mediação das interações; (e) definição das regras de convivência do grupo; (f) caracterização da comunidade digital; (g) mapeamento das ferramentas e recursos da mídia social Facebook® e escolha daquelas que seriam utilizadas pelo grupo; (h) definição das ações a serem feitas para manter o grupo direcionado no propósito da comunidade de prática a ser criada. As sugestões apontadas pelos membros do grupo foram registradas e categorizadas, contribuindo para a elaboração da proposta da CoP digital: uma plataforma dotada de recursos que permitam a aprendizagem através da colaboração e troca de experiências entre os participantes.

(3) Desenvolvimento - nesta etapa desenvolveu-se aplicou-se o artefato em si (método para criação da comunidade), com os ajustes necessários, para que pudesse ser testado e avaliado. Em 20 de setembro de 2014 foi então criada uma comunidade no Facebook®, pelos próprios participantes, seguindo todos os passos listados na etapa anterior e contando com a ajuda da pesquisadora principal do estudo. A comunidade foi então observada em funcionamento por 5 meses seguidos (até 20 de fevereiro de 2015), data limite estabelecida para a conclusão da pesquisa.

(4) Avaliação - a avaliação da comunidade realizou-se de maneira contínua, através do acompanhamento diário das atividades registradas no Facebook® (atividades individuais ou grupais, posts e curtidas, compartilhamentos de conteúdo, perguntas, projetos, etc.). Também foram realizadas entrevistas, ao final do estudo, que buscaram entender com mais profundidade a percepção dos participantes a respeito da vivência na comunidade e contribuições desta para o seu desenvolvimento profissional. Os dados textuais gerados na comunidade e por meio das entrevistas foram categorizados e analisados através do método de análise de conteúdo, definido por Chizzotti (2006) como um conjunto de técnicas de análise de comunicações, que tem como objetivo compreender criticamente o sentido das comunicações, seu conteúdo manifesto ou latente, as significações explícitas ou ocultas. A análise dos dados coletados foi realizada através do software NVivo®, que permite analisar e categorizar diferentes tipos de dados (textos, figuras, sites, links, vídeos, etc.).

(5) Conclusões - nesta fase foram consolidados, registrados e divulgados os resultados

$$
\text { REAd | Porto Alegre - Vol. } 23 \text { - No Especial - Dezembro } 2017 \text { - p. 93-125 }
$$


da pesquisa, conforme será apresentado a seguir.

\section{ANÁLISE DOS DADOS}

Nesta seção serão apresentados os principais resultados da pesquisa, seguindo as etapas da metodologia proposta (Design Science Research).

\subsection{ENTENDIMENTO OU CONSCIENTIZAÇÃO DO PROBLEMA}

Os principais sujeitos da pesquisa foram 41 alunos de um curso técnico profissionalizante de Manutenção Elétrica e Predial oferecido pelo SENAI, classificados como sócio-vulneráveis, beneficiados pelo programa do governo federal "Aprendiz Industrial" por meio de cotas de aprendizagem. Para compor o estudo foram também convidados a participar do grupo 05 professores de diferentes cursos ministrados pela instituição (Manutenção Elétrica, Manutenção Predial, Eletrônica, Automação Industrial, Mecânica Industrial) e 1 supervisor educacional. Além dos professores, a pesquisadora, docente na área de Gestão Administrativa, também foi inclusa no grupo para atuar no papel de colaboradora da comunidade. Portanto, a comunidade criada contava ao todo com 48 membros. Cabe ressaltar que em sua totalidade, os membros tiveram uma participação voluntária na comunidade e na pesquisa.

O Quadro 1 apresenta uma síntese das principais informações coletadas na etapa de entendimento do problema a respeito do perfil dos estudantes e o contexto tecnológico no qual estão inseridos (informações levantadas por meio de questionário aplicado junto aos 43 alunos).

Quadro 1 - Síntese das principais informações sobre o perfil dos alunos participantes

(continua)

\begin{tabular}{|l|l|l|}
\hline \multicolumn{1}{|c|}{ Características } & \multicolumn{1}{|c|}{ Perfil dos respondentes } & \multicolumn{1}{c|}{ Observações } \\
\hline Sexo & $\begin{array}{l}\text { A maioria são homens (88\%), mulheres } \\
\text { correspondem a 12\% }\end{array}$ & \\
\hline Idade média & 17 anos & $\begin{array}{l}\text { Ensino médio concluído (21\%) ou } \\
\text { cursando ensino fundamental (9\%) }\end{array}$ \\
\hline Nível de escolaridade & Ensino médio (70\%) & $\begin{array}{l}\text { Com algum tipo de experiência } \\
\text { profissional (70\%), porém fora da área de } \\
\text { manutenção elétrica (86\%) }\end{array}$ \\
\hline $\begin{array}{l}\text { Experiências } \\
\text { profissionais }\end{array}$ & $\begin{array}{l}\text { Por smartphones }(82 \%) \text { e/ou computadores } \\
\text { fixos (72\%) }\end{array}$ & $\begin{array}{l}\text { Também notebooks (58\%) e tablets } \\
(21 \%)\end{array}$ \\
\hline $\begin{array}{l}\text { Meios de acesso à } \\
\text { internet }\end{array}$ & Rede doméstica (81\%) ou celular (74\%) & \\
\hline $\begin{array}{l}\text { Formas de conexão } \\
\text { com a internet }\end{array}$ &
\end{tabular}

REAd | Porto Alegre - Vol. 23 - No Especial - Dezembro 2017 - p. 93-125 
Quadro 1 - Síntese das principais informações sobre o perfil dos alunos participantes

\begin{tabular}{|c|c|c|}
\hline Uso de mídias sociais & $\begin{array}{l}\text { Facebook® }(100 \%) \text { e Whatsapp } ®(81 \%) \\
\text { diariamente. }\end{array}$ & $\begin{array}{l}\text { Outras mídias: Youtube } \AA(65 \%) \text {, } \\
\text { Instagram }{ }^{\circledR}(35 \%) .\end{array}$ \\
\hline Uso do Facebook ${ }^{\circledR}$ & Todos $(100 \%)$ & \\
\hline $\begin{array}{l}\text { Rotinas de acessos ao } \\
\text { Facebook } \circledR\end{array}$ & A maioria $(85 \%)$ acessa diariamente. & $\begin{array}{l}15 \% \text { acessam de duas a três vezes } \\
\text { por semana. }\end{array}$ \\
\hline Período de acesso & Nos três turnos do dia $(58 \%)$ & \\
\hline $\begin{array}{l}\text { Tempo de permanência } \\
\text { no Facebook } \AA\end{array}$ & $\begin{array}{l}\text { Entre } 1 \text { e } 3 \text { horas diárias, para mais da } \\
\text { metade dos participantes }(53 \%)\end{array}$ & \\
\hline $\begin{array}{l}\text { Participação em grupos } \\
\text { do Facebook } ₫\end{array}$ & $\begin{array}{l}\text { A maioria (88\%) faz parte de grupos no } \\
\text { Facebook® }\end{array}$ & \\
\hline Formas de interação & $\begin{array}{l}\text { Comentários }(53 \%) \text {, curtidas }(53 \%), \\
\text { postagens }(49 \%) .\end{array}$ & $\begin{array}{l}\text { O recurso visualizar foi citado por } \\
16 \% \text { como forma de participação em } \\
\text { grupos. }\end{array}$ \\
\hline $\begin{array}{l}\text { Participação em grupo } \\
\text { do Facebook } ® \text { para } \\
\text { desenvolvimento } \\
\text { profissional }\end{array}$ & $\begin{array}{l}\text { Todos }(100 \%) \text { responderam que fariam } \\
\text { parte de um grupo no Facebook® voltado } \\
\text { para seu desenvolvimento profissional. }\end{array}$ & \\
\hline $\begin{array}{l}\text { Temas sugeridos para a } \\
\text { comunidade a ser } \\
\text { criada no Facebook®. }\end{array}$ & $\begin{array}{l}\text { Respostas diversas: informações da área } \\
(79 \%) \text {, vídeos sobre os temas }(77 \%) \text {, } \\
\text { mercado de trabalho }(60 \%) \text {, vagas de } \\
\text { trabalho }(58 \%) \text {, experiências profissionais } \\
(51 \%)\end{array}$ & \\
\hline
\end{tabular}

Fonte: dados da pesquisa.

A análise dos dados nesta primeira etapa da Design Science Research permitiu concluir que o grupo selecionado encontrava-se dentro das expectativas da pesquisa, apresentando um perfil socioeconômico vulnerável que busca desenvolvimento profissional, através da qualificação técnica e que, apesar da baixa renda, possui acesso às mídias sociais.

\subsection{SUGESTÕES}

Como base na análise do perfil dos participantes e nas discussões conjuntas com eles, apoiadas pela literatura sobre CoP, iniciou-se o processo de criação do artefato interativamente. É importante destacar esta etapa de sugestões seguiu premissas apontadas por Freire (1996) para a aprendizagem através da autonomia, pela qual membros de um grupo tomam decisões, buscam explorar suas próprias curiosidades no processo de aprendizagem e desenvolvem práticas conjuntas que os levam ao alcance de metas comunitárias. O quadro 2 apresenta as principais definições do grupo para criar a $\mathrm{CoP}$ digital.

Além da participação em eventos educacionais, as sugestões trazidas pelos estudantes foram de utilização da comunidade digital no Facebook® como um espaço de troca de conhecimento relativos a temas de mercado de trabalho e desenvolvimento profissional. Os assuntos sugeridos foram: sites, cursos, oportunidades de emprego, experiências na área, 
relacionamento interpessoal, aprendizagens sobre imagem, postura, etc.

Quadro 2 - Definições da comunidade de prática criada

\begin{tabular}{|l|l|}
\hline Aspectos & \multicolumn{1}{c|}{ Definições realizadas pelos participantes } \\
\hline Objetivos da CoP & $\begin{array}{l}\text { Desenvolvimento de projetos inovadores na área de Elétrica. } \\
\text { Participação dos membros no evento Mundo SENAI. } \\
\text { Preparação para as Olimpíadas do Conhecimento. } \\
\text { Criação de um espaço para troca de informações sobre: mercado de trabalho, } \\
\text { comportamento, postura, relacionamento interpessoal, segurança do trabalho, entre } \\
\text { outros assuntos voltados para a área. }\end{array}$ \\
\hline $\begin{array}{l}\text { Configurações de } \\
\text { privacidade }\end{array}$ & Grupo fechado - somente os membros podem ter acesso às publicações. \\
\hline Perfil & $\begin{array}{l}\text { Nome: Grupo Volt } \\
\text { Símbolo: logo próprio, escolha feita de forma digital (votação). } \\
\text { Apresentação: Publicação fixada no mural do grupo. } \\
\text { Foto de capa: o símbolo do grupo. }\end{array}$ \\
\hline Membros externos & Convite para membros externos feito pelos líderes, através do recurso mensagem. \\
\hline Apoiadores & Padrinhos da comunidade: professores das áreas técnicas e de gestão. \\
\hline $\begin{array}{l}\text { Recursos de } \\
\text { interação }\end{array}$ & $\begin{array}{l}\text { Postagens } \\
\text { Compartilhamento de informações e conteúdos } \\
\text { Comentários } \\
\text { Curtidas } \\
\text { Visualização } \\
\text { Notificações por e-mail } \\
\text { Chat (bate-papo) }\end{array}$ \\
\hline
\end{tabular}

Fonte: dados da pesquisa.

Nesta etapa foram escolhidos líderes para representar o grupo e realizar a criação efetiva da comunidade no Facebook®, conforme as definições estabelecidas pelo grupo. O quadro 3 apresenta as ações do início deste processo.

Quadro 3 - Processo de criação digital da CoP

\begin{tabular}{|l|l|}
\hline Descrição & \multicolumn{1}{c|}{ Ações no Facebook® } \\
\hline $\begin{array}{l}\text { Criação do } \\
\text { grupo }\end{array}$ & $\begin{array}{l}\text { A criação do grupo no Facebook® foi realizada por um dos líderes da comunidade, por } \\
\text { meio da ferramenta "Criar Grupo". }\end{array}$ \\
\hline $\begin{array}{l}\text { Inclusão de } \\
\text { membros }\end{array}$ & $\begin{array}{l}\text { Os membros foram adicionados ao grupo pelos líderes.Cabe destacar que após a inclusão, o } \\
\text { participante também pode adicionar ao grupo pessoas de sua rede de contatos. }\end{array}$ \\
\hline Configurações & $\begin{array}{l}\text { O Facebook® possui uma série de configurações para grupos. A CoP teve sua configuração } \\
\text { efetuada pelos líderes, seguindo as decisões acertadas entre os membros. Assim, definiu-se: } \\
\text { Privacidade - grupo fechado (somente os membros podem ver as configurações); } \\
\text { Membros - livre (qualquer membro pode adicionar outro membro); } \\
\text { Publicações - livre (qualquer membro pode publicar no grupo); } \\
\text { Notificações - permitida para todas as publicações. }\end{array}$ \\
\hline
\end{tabular}

Fonte: dados da pesquisa

\subsection{DESENVOLVIMENTO}

Após a criação da comunidade, passou-se acompanhar o seu desenvolvimento no espaço digital. Nesse momento do estudo cabe destacar que os participantes interagiram não só 
através do Facebook®, pelo fato do grupo ser composto por estudantes que dividiam espaço em sala de aula presencial; debates, troca de ideias, dúvidas também ocorreram presencialmente.

No período de desenvolvimento (setembro de 2014 a fevereiro de 2015 - 5 meses), foram realizadas pelos membros dentro do ambiente digital, ao todo, 60 publicações, contendo diferentes conteúdos (textos, vídeos, links, figuras, etc.). Para organizar as análises, realizou-se uma divisão das publicações em categorias. As categorias de análise foram estabelecidas por codificação aberta, de acordo com a origem e conteúdo das comunicações na comunidade. Definiram-se primeiramente quatro tipos de categorias: comunicações informais, demonstrações de trabalhos, informações de terceiros e resoluções de problemas.

- Comunicações diversas - referem-se às publicações como textos, frases motivacionais, atividades entre os membros, fotos do grupo, que apresentaram conteúdos diversos (profissionais, acadêmicos, identidade do grupo, etc.).

- Demonstrações de trabalho - publicações onde os membros expõem para o grupo informações (foto, vídeos, textos) referentes aos seus trabalhos de aprendizagem, sejam estes projetos, inovações, páginas criadas para serviço, etc.

- Informações de terceiros - publicações referentes a informações (textos, vídeos, links, notícias) oriundas de pessoas que não fazem parte da comunidade digital (contatos dos membros no Facebook $®)$. Essas publicações são vistas pelos membros da comunidade digital em suas páginas pessoais do Facebook @ e compartilhadas por eles na página do grupo, como uma forma de repassar informações externas a respeito dos temas de interesse comuns.

- Resoluções de problemas - publicações feitas pelos membros com pedidos de ajuda para a resolução de problemas, solução de dúvidas, dificuldades de aprendizagem, etc.

Dentro dessas quatro categorias foi feita também uma divisão por conteúdo de acordo com os temas das publicações, assim houve uma separação em: áreas técnicas (conteúdos referentes a informações da área de manutenção elétrica), identidade do grupo (elementos relacionados à criação de características para o grupo), profissional (informações sobre mercado de trabalho, vagas, cursos, currículo, etc.) e projetos de aprendizagem (conteúdos relativos aos projetos criados pelos membros para o evento Mundo SENAI). A Tabela 1 apresenta um cruzamento entre as categorias e seus conteúdos.

Em uma análise geral dos dados (Tabela 1), verifica-se que $42 \%$ das publicações estão relacionadas a informações de terceiros, $22 \%$ referem-se a demonstrações de trabalho, e $22 \%$ relacionam-se a comunicações diversas. Apenas 14\% são consideradas publicações destinadas 
à resolução de problemas. Os dados revelam que conteúdos relativos a áreas técnicas estão presentes em $33 \%$ das postagens, os projetos de aprendizagem representam $22 \%$ do conteúdo total, informações referentes à área profissional não técnica em $21 \%$ do total e os dados que compõem a identidade da comunidade aparecem em 15\% do total de conteúdos das publicações.

Tabela 1: Categorias e conteúdo das publicações

\begin{tabular}{cccccc}
\hline \multirow{2}{*}{$\begin{array}{c}\text { Conteúdo das } \\
\text { publicações }\end{array}$} & $\begin{array}{c}\text { Comunicações } \\
\text { Diversas }\end{array}$ & $\begin{array}{c}\text { Demonstrações de } \\
\text { trabalhos }\end{array}$ & $\begin{array}{c}\text { Informações } \\
\text { de } \\
\text { terceiros }\end{array}$ & $\begin{array}{c}\text { Resoluções } \\
\text { de } \\
\text { problemas }\end{array}$ & $\begin{array}{c}\text { Total de } \\
\text { publicações }\end{array}$ \\
\cline { 2 - 6 } & 0 & 0 & 20 & 0 & $\mathbf{2 0}(\mathbf{3 3 \%})$ \\
\hline $\begin{array}{c}\text { Áreas técnicas } \\
\text { Identidade do grupo }\end{array}$ & 9 & 0 & 0 & 0 & $\mathbf{9}(\mathbf{1 5 \%})$ \\
$\begin{array}{c}\text { Profissional } \\
\text { (não técnico) }\end{array}$ & 4 & 0 & 5 & 4 & $\mathbf{1 3}(\mathbf{2 1 \%})$ \\
$\begin{array}{c}\text { Projetos de } \\
\text { aprendizagem } \\
\text { Quantidade total }\end{array}$ & 0 & 13 & 0 & $\mathbf{1 8}(\mathbf{3 0 \%})$ \\
\hline & $\mathbf{1 3}(\mathbf{2 2 \%})$ & Fonte: dados da pesquisa. & $\mathbf{2 5}(\mathbf{4 2 \%})$ & $\mathbf{9}(\mathbf{1 4 \%})$ & $\mathbf{6 0}(\mathbf{1 0 0 \%})$ \\
\hline
\end{tabular}

Para este estudo, as publicações foram consideradas como um dos principais elementos de análise, já que os recursos que permitem interação em grupos do Facebook® (comentários, curtidas, visualizações) advém das publicações. Além disso, por meio das publicações tornou-se possível o enquadramento dos membros nos diferentes níveis de participação descritos para uma CoP.

Durante o período de desenvolvimento, a utilização de cada um dos recursos pelos membros foi registrada de forma quantitativa para que um número médio de interações comunitárias pudesse ser estabelecido. Os resultados estão expressos na Tabela 2.

Tabela 2 - Média das interações na comunidade digital no Facebook®

\begin{tabular}{lccc}
\hline Recurso doFacebook ${ }^{\circledR}$ & $\begin{array}{c}\text { Quantidade total de } \\
\text { interações }\end{array}$ & $\begin{array}{c}\text { Quantidade de } \\
\text { membros }\end{array}$ & $\begin{array}{c}\text { Média de } \\
\text { interações/membro }\end{array}$ \\
\hline Publicações & 60 & 48 & 1,3 \\
Comentários & 54 & 48 & 1,2 \\
Curtidas & 260 & 48 & 5,7 \\
Visualizações & 1660 & 48 & 36 \\
\hline
\end{tabular}

Fonte: dados da pesquisa.

De acordo a Tabela 2, na comunidade no Facebook ${ }^{\circledR}$ ocorreu em média 1,3 publicações por participante. No recurso comentários, que permite ao participante contribuir com a sua opinião ou experiência a respeito do tema publicado, foram registrados 1,2 comentários por membro. Esse resultado demonstra que os temas publicados geraram pouca discussão entre os participantes, podendo-se dizer assim que o nível de interação comunitária foi baixo. É REAd | Porto Alegre - Vol. 23 - No Especial - Dezembro 2017 - p. 93-125 
possível pressupor que isso esteja relacionado ao fato dos integrantes disporem de outros canais de comunicação que não somente a mídia social. Verificou-se, por meio das entrevistas e observação, que o grupo interagiu através de contato presencial e demais aplicativos digitais (mensagens $S M S$ e via WhatsApp ${ }^{\circledR}$ ) para conversas, dúvidas, relatos e pedidos de ajuda entre os membros.

O recurso curtidas, que tem como função expressar uma avaliação positiva com relação ao que foi publicado, apresentou um número médio de 5,7 curtidas por membro. Esse resultado pode demonstrar, além de uma interação baixa, que as publicações não causaram grande interesse nos participantes.

Já o recurso visualizações foi utilizado, para cada publicação, em média por 36 membros, ou seja, cada publicação foi visualizada, em média, por $75 \%$ dos membros. Esse número pode traduzir um tipo de acesso considerado mais passivo, ou seja, membros que não interagem por meio de comentários ou troca de experiências, mas que acompanham as ações da comunidade como observadores.

Dentro dessa lógica, buscou-se estabelecer um relação entre os níveis de participação dos membros da comunidade digital Facebook®, e o conceito de nível de engajamento em CoP de Wenger et al.(2002). Para isso, estabeleceu-se uma classificação estatística de quartis, apresentada na Tabela 3, na qual as atividades individuais dos membros (postagens, comentários, curtidas e visualizações), foram enquadradas de acordo com:

- Quartil superior - composto pelos $25 \%$ maiores = membros mais atuantes da amostra ordenada;

- Mediana - composto por até $50 \%$ da amostra ordenada = membros com atuação média na comunidade;

- Quartil inferior - composto pelos $25 \%$ menores ou menos atuantes (participação periférica).

Com relação ao elemento principal, publicações, as análises enquadram no quartil superior os $25 \%$ com maior publicação, são 16 membros que realizaram de 0 a 21 publicações no grupo.

Os comentários, provenientes das publicações enquadram no quartil superior os $25 \%$ que mais comentaram no grupo, são 12 membros que realizaram de 0 a 16 comentários de postagens no espaço comunitário.A análise do recurso curtir enquadrou no quartil superior os 25\% com maior curtidas, são 13 membros que realizaram de 9 a 35 curtidas nas publicações ou nos comentários feitos no grupo. O último recurso analisado foram as visualizações que 
enquadram no quartil superior os $25 \%$ com maior visualização, são 16 membros que realizaram de 48 a 55 visualizações nas publicações feitas no grupo.

Tabela 3 - Análise de participação na comunidade, por quartis

\begin{tabular}{|c|c|c|c|c|c|}
\hline Variável & Grupo & $\begin{array}{c}\mathrm{N}^{\mathbf{0}} \text { de } \\
\text { participantes }\end{array}$ & $\begin{array}{l}\text { Intervalo dos } \\
\text { membros } \\
\end{array}$ & Média & $\begin{array}{l}\text { Desvio } \\
\text { Padrão } \\
\end{array}$ \\
\hline \multirow{3}{*}{ Visualização } & $25 \%$ menores & 14 & De 0 a 29 & 8,09 & 8,42 \\
\hline & $25 \%$ maiores & 16 & De 48 a 55 & 50,58 & 2,43 \\
\hline & Mediana & 18 & Entre 40 a 46 & 43,90 & 2,38 \\
\hline \multirow{3}{*}{ Publicação } & $25 \%$ menores & 32 & 0 & 0 & 0 \\
\hline & $25 \%$ maiores & 16 & De 0 a 21 & 4,29 & 5,41 \\
\hline & Mediana & 0 & - & - & - \\
\hline \multirow{3}{*}{ Curtida } & $25 \%$ menores & 14 & 0 & 0,00 & 0,00 \\
\hline & $25 \%$ maiores & 13 & De 9 a 35 & 15,92 & 8,13 \\
\hline & Mediana & 21 & Entre 1 a 4 & 2,29 & 1,31 \\
\hline \multirow{3}{*}{ Comentário } & $25 \%$ menores & 36 & 0 & 0,00 & 0,00 \\
\hline & $25 \%$ maiores & 12 & De 0 a 16 & 5,40 & 5,60 \\
\hline & Mediana & 0 & - & - & - \\
\hline
\end{tabular}

Fonte: dados da pesquisa.

Por meio da análise de quartis foi possível estabelecer, de maneira ampla, uma conexão com o grau de participação descrito por Wenger et al. (2002) que classifica o nível de engajamento dos participantes em CoP. O Quadro 4 apresenta essa divisão e traz exemplos das atividades consideradas para a classificação dentro de cada quartil.

Quadro 4 - Grau de participação dos membros da comunidade na divisão em quartis

\begin{tabular}{|c|c|c|c|}
\hline Quartil & $\begin{array}{c}\text { Grau de } \\
\text { participação }\end{array}$ & $\begin{array}{c}\text { Definiç̧ão } \\
\text { (WENGER et al., 2002) }\end{array}$ & $\begin{array}{c}\text { Exemplos de atividades dos } \\
\text { membros na comunidade }\end{array}$ \\
\hline Superior & Central $(25 \%)$ & $\begin{array}{l}\text { Composto por pessoas que participam } \\
\text { ativamente das discussões e debates nos } \\
\text { fóruns públicos, assumindo projetos da } \\
\text { comunidade, identificando assuntos para } \\
\text { tratar e movimentando a agenda de } \\
\text { aprendizado da comunidade. }\end{array}$ & $\begin{array}{l}\text { Publicações } \\
\text { Comentários } \\
\text { Curtidas } \\
\text { Participação em eventos } \\
\text { Criação de artefatos } \\
\text { Projetos colaborativos }\end{array}$ \\
\hline Mediana & Ativos $(50 \%)$ & $\begin{array}{l}\text { As pessoas deste grupo participam } \\
\text { regularmente das atividades, porém sem a } \\
\text { intensidade do grupo central. }\end{array}$ & $\begin{array}{l}\text { Mesmas atividades do grupo } \\
\text { central, porém com } \\
\text { participação menos intensa } \\
\text { ou esporádica dos membros. }\end{array}$ \\
\hline Inferior & $\begin{array}{l}\text { Periféricos } \\
(25 \%)\end{array}$ & $\begin{array}{l}\text { Composto pela grande maioria dos } \\
\text { participantes. }\end{array}$ & Visualizações \\
\hline
\end{tabular}
Fonte: dados da pesquisa.

Assim, ao analisar os níveis de participação dos membros a partir de iniciativas autônomas de pesquisa e compartilhamento de informações com o grupo, foi possível identificar, ao menos no grupo mais ativo dentro da comunidade, atitudes de proatividade, liberdade, interações, criatividade e responsabilidade, tanto individuais quanto em equipe. Cabe destacar que essas práticas podem contribuir com a aprendizagem, com benefícios que 
vão desde a facilidade de uso das mídias sociais até a criação de um senso de pertencimento ao grupo.

No entanto, acredita-se que um fator que contribuiu para o baixo número de interações pode estar relacionado à própria condição social (de vulnerabilidade) dos participantes do grupo, pois percebeu-se que a maior parte deles demonstrava uma grande dificuldade em expressar-se publicamente, tanto na forma presencial quanto na digital. Observou-se que o vocabulário dos participantes era bastante limitado, o que pode ter dificultado sua comunicação dentro do ambiente digital.

\subsection{AVALIAÇÃO DOS RESULTADOS}

Após ter-se acompanhado o desenvolvimento das interações dentro da comunidade, fezse uma avaliação de como ela foi desenvolvida, o quanto o Facebook® oferece suporte ou não a uma $\mathrm{CoP}$ e o quanto a comunidade contribuiu ou não para o desenvolvimento profissional do grupo participante (sócio vulnerável). Seguindo o método de design science research, essa avaliação é feita à luz dos conceitos teóricos que embasaram a criação do artefato (método de criação de uma CoP usando a mídia social Facebook®).

Inicialmente foi analisada a viabilidade do uso do Facebook® como plataforma para a criação de uma CoP, utilizando-se os conceitos de Tucker (2012) a respeito de CoP virtuais. Para a autora, as CoP virtuais têm o objetivo de ajudar a gerenciar o conhecimento e proporcionar interação entre os participantes, sendo atualmente um dos sistemas mais utilizados pelas organizações devido à infraestrutura tecnológica e à consistência de agregação de participantes - ver Quadro 5.

Quadro 5 - Características de CoP virtuais presentes na comunidade virtual no Facebook®

\begin{tabular}{|c|c|c|}
\hline $\begin{array}{l}\text { Características de } \\
\text { CoPs virtuais } \\
\text { (TUCKER, 2012) }\end{array}$ & $\begin{array}{c}\text { Presente na } \\
\text { comunidade } \\
\text { criada no } \\
\text { Facebook } ₫ ?\end{array}$ & Exemplos de recursos \\
\hline $\begin{array}{l}\text { Identificação dos } \\
\text { participantes, } \\
\text { diretórios e perfis }\end{array}$ & SIM & $\begin{array}{l}\text { Adicionar membros ao grupo } \\
\text { Os participantes da comunidade virtual foram inclusos no grupo } \\
\text { através do recurso do Facebook }{ }^{\circledR} \text { "adicionar membros", que } \\
\text { permite, além da inclusão, uma breve identificação do perfil } \\
\text { participante. }\end{array}$ \\
\hline $\begin{array}{l}\text { Espaço para discussão } \\
\text { assíncrona e síncrona } \\
\text { (bate-papo) }\end{array}$ & SIM & $\begin{array}{l}\text { Publicar, comentar, compartilhar, bate-papo } \\
\text { Os membros da comunidade virtual realizaram publicações } \\
\text { (texto, fotos, vídeos, arquivos), geraram discussões e opiniões } \\
\text { entre os participantes por meio de comentários e respostas. Os } \\
\text { participantes utilizaram também o recurso bate-papo on-line, } \\
\text { para a troca de informações e esclarecimento de dúvidas. }\end{array}$ \\
\hline
\end{tabular}


Quadro 5 - Características de CoP virtuais presentes na comunidade virtual no Facebook®

\begin{tabular}{|c|c|c|}
\hline $\begin{array}{l}\text { Visualizador de } \\
\text { presença, mensagens } \\
\text { imediatas }\end{array}$ & SIM & $\begin{array}{l}\text { Visualizar publicação } \\
\text { O Facebook }{ }^{\circledR} \text { possui o recurso "visualizar" que permite } \\
\text { identificar os participantes que visualizaram as publicações } \\
\text { feitas no espaço do grupo, de forma imediata. } \\
\text { A visualização foi utilizada pelos membros da comunidade } \\
\text { virtual e permitiu atribuir o grau de engajamento "periférico" } \\
\text { para aqueles que fizeram uso somente deste recurso como forma } \\
\text { de interação. }\end{array}$ \\
\hline $\begin{array}{l}\text { Características de } \\
\text { CoPs virtuais } \\
\text { (TUCKER, 2012) }\end{array}$ & $\begin{array}{c}\text { Presente na } \\
\text { comunidade } \\
\text { criada no } \\
\text { Facebook } \AA \text { ? }\end{array}$ & Exemplos de recursos \\
\hline $\begin{array}{l}\text { Ferramentas de } \\
\text { avaliação }\end{array}$ & NÃO & $\begin{array}{l}\text { Discussão - opção: perguntar } \\
\text { O Facebook }{ }^{\circledR} \text { possui recursos como "perguntar" onde é } \\
\text { possível criar opções de resposta para avaliar uma ideia, assunto } \\
\text { ou afins. Este recurso estava disponível, mas não foi utilizado } \\
\text { na comunidade virtual. }\end{array}$ \\
\hline $\begin{array}{l}\text { Customização de } \\
\text { espaço de comunidade }\end{array}$ & SIM & $\begin{array}{l}\text { Personalização } \\
\text { O Facebook® possui diversos recursos para a customização de } \\
\text { grupos virtuais. } \\
\text { Entre os recursos utilizados pela comunidade destacam-se: } \\
\text { Foto de capa com nome e logotipo criado pelos membros. } \\
\text { Privacidade: grupo fechado, somente para participantes } \\
\text { inclusos. } \\
\text { Álbum: fotos do grupo e seus participantes. } \\
\text { Publicação fixa: boas vindas e declaração da proposta do grupo. }\end{array}$ \\
\hline $\begin{array}{l}\text { Espaço para criação de } \\
\text { sub-comunidades }\end{array}$ & NÃO & $\begin{array}{l}\text { Criar novo grupo } \\
\text { O Facebook } ₫ \text { possui o recurso de criação de grupos, que torna } \\
\text { possível que a comunidade crie as suas sub-comunidades ou } \\
\text { sub-grupos.A comunidade virtual, no entanto, não fez uso desse } \\
\text { recurso. }\end{array}$ \\
\hline Calendário de eventos & $\mathrm{NÃO}$ & $\begin{array}{l}\text { Criar evento } \\
\text { O Facebook® permite a criação de eventos ou calendário de } \\
\text { acontecimentos importantes. A comunidade virtual, no entanto, } \\
\text { não fez uso desse recurso. }\end{array}$ \\
\hline Análise de atividade & SIM & $\begin{array}{l}\text { Linha do tempo - O Facebook® permite a exposição de todas } \\
\text { as publicações desde a criação do grupo até o momento atual. } \\
\text { Além disso, o Facebook }{ }^{\circledR} \text { armazena todas as publicações, } \\
\text { visualizações, comentários e avaliações (curtidas) feitas pelos } \\
\text { integrantes do grupo. }\end{array}$ \\
\hline $\begin{array}{l}\text { Ferramentas de } \\
\text { administração }\end{array}$ & SIM & $\begin{array}{l}\text { Administração do grupo - O Facebook }{ }^{\circledR} \text { possui o recurso de } \\
\text { administração para os grupos. Na comunidade virtual o } \\
\text { administrador escolhido ficou responsável pelas configurações } \\
\text { do grupo. }\end{array}$ \\
\hline
\end{tabular}

Fonte: dados da pesquisa.

Pela análise realizada no Quadro 5 é possível verificar que o Facebook® possui os principais recursos necessários para a criação de uma $\mathrm{CoP}$ virtual, ainda que o grupo pesquisado não tenha utilizado todos os recursos disponíveis, que inclusive são apontados pela literatura.

Contudo, a análise dos dados buscou ir a fundo para compreender se a comunidade virtual constituída possuía de fato as características de uma CoP. Wenger (2001) elenca as três 
dimensões principais que definem uma comunidade como sendo de prática: o domínio, a comunidade e a prática. Neste estudo, esses elementos puderam ser evidenciados em maior ou menor grau de intensidade, conforme é apresentado no quadro 6.

Quadro 6 - Relação entre as dimensões das CoP e a comunidade virtual no Facebook®

\begin{tabular}{|c|c|c|}
\hline Elementos & $\begin{array}{c}\text { Definição } \\
\text { (WENGER, 2001) }\end{array}$ & $\begin{array}{c}\text { Aspectos da comunidade criada } \\
\text { noFacebook } ®\end{array}$ \\
\hline Domínio & $\begin{array}{l}\text { Uma comunidade de prática deve ter uma identidade } \\
\text { definida por um domínio de interesse comum, } \\
\text { compartilhado entre os membros. Bem definido, o } \\
\text { domínio legitima a comunidade pela afirmação dos } \\
\text { propósitos e valores dos membros e de outros atores } \\
\text { interessados. }\end{array}$ & $\begin{array}{l}\text { O domínio, ou interesse, foi a } \\
\text { aprendizagem na área de } \\
\text { manutenção elétrica. }\end{array}$ \\
\hline Comunidade & $\begin{array}{l}\text { Muitos grupos de interesse partilham domínios } \\
\text { comuns, porém se não interagem e aprendem juntos, } \\
\text { não formam uma CoP. O elemento chave da } \\
\text { comunidade é a interação, que desenvolve } \\
\text { relacionamentos, fortalecendo a confiança entre os } \\
\text { membros do grupo. }\end{array}$ & $\begin{array}{l}\text { Baixa interação entre os } \\
\text { membros. As publicações feitas na } \\
\text { comunidade virtual fomentaram } \\
\text { poucas discussões ou reflexões } \\
\text { que levam à prática. Presença de } \\
\text { comportamento narcisista e } \\
\text { relações superficiais. }\end{array}$ \\
\hline Prática & $\begin{array}{l}\text { A prática de uma comunidade é dinâmica e envolve a } \\
\text { aprendizagem por parte de cada um. Para uma CoP } \\
\text { funcionar ela precisa gerar e se apropriar de um } \\
\text { repertório compartilhado de ideias, compromissos } \\
\text { e memórias. Também precisa desenvolver vários } \\
\text { recursos e artefatos. }\end{array}$ & $\begin{array}{l}\text { O grupo desenvolveu relações } \\
\text { informais, características de uma } \\
\text { rede de informações, mas não de } \\
\text { uma comunidade de prática. } \\
\text { Houve criação de alguns artefatos } \\
\text { (logo, vídeos). }\end{array}$ \\
\hline
\end{tabular}

Fonte: dados da pesquisa.

Com relação ao domínio, este foi estabelecido em torno do tema de interesse do grupo: a área de manutenção elétrica. Direcionado por esse foco, os membros realizaram a prática de ações como: pesquisa, projetos, eventos, troca de conhecimentos.

A dimensão comunidade está relacionada ao nível de interações do grupo. Como já foi demonstrado, durante o período da pesquisa foi registrada uma média por membro de 1,3 publicações e 1,2 comentários, respectivamente, no espaço virtual. A média foi considerada baixa e nas entrevistas finais verificou-se que alguns participantes preferiam não publicar no Facebook® em função do julgamento que podiam sofrer por outros membros. Esse comportamento pode estar relacionado ao chamado narcisismo em mídias sociais (PAPACHARISSI, 2010; CARPENTER, 2012; RYAN; XENOS, 2011), pois as pessoas tornam públicas apenas as informações que consideram apropriadas para a formação de uma imagem desejada de autoimportância ou singularidade. Nessas mídias sociais há uma certa incapacidade de tolerar críticas e a expectativa de obter favores especiais sem assumir responsabilidades recíprocas, estabelecendo assim apenas relações superficiais. Esse fator precisa ser levado em conta na criação de uma CoP em mídias sociais como o Facebook®. 
Possivelmente devido à baixa interação entre os membros, a dimensão prática desenvolveu-se pouco, sendo mais evidente no sentido de repasse de informações sobre a área profissional de maneira informal. Estabelecer conexões informais entre os membros, para Alle (2000), seria o objetivo principal de uma rede, mas estar em rede não significa estar em comunidade.

Para analisar porque houve dificuldade em criar efetivamente uma comunidade de prática no Facebook®, considerou-se os elementos básicos para a sua consolidação (WENGER, 2001): os eventos, a liderança, a conectividade, a filiação, os projetos de aprendizagem e artefatos. A comunidade no Facebook® apresentou a maioria dos elementos básicos necessários para o desenvolvimento de uma CoP. O quadro 7 apresenta um painel desses aspectos, relacionando teoria e prática.

Quadro 7 - Elementos de uma comunidade de prática

(continua)

\begin{tabular}{|c|c|c|}
\hline Elementos & $\begin{array}{l}\text { Conceitos teóricos } \\
\text { (WENGER, 2001) }\end{array}$ & $\begin{array}{c}\text { Aspectos observados na comunidade } \\
\text { virtual }\end{array}$ \\
\hline Eventos & $\begin{array}{l}\text { A organização de eventos promove a união } \\
\text { da comunidade. Atendendo ou não os } \\
\text { objetivos propostos, ajudam a desenvolver } \\
\text { o senso de identidade. É a comunidade que } \\
\text { irá decidir os tipos de eventos necessários } \\
\text { para o seu desenvolvimento: informais, } \\
\text { sessões de resolução de problemas, } \\
\text { perguntas e respostas. }\end{array}$ & $\begin{array}{l}\text { Os membros da comunidade virtual } \\
\text { participaram de alguns eventos, tanto } \\
\text { formais quanto informais. } \\
\text { Podem ser destacados: Mundo SENAI; } \\
\text { reuniões em grupos de trabalho; encontros } \\
\text { informais. }\end{array}$ \\
\hline Conectividade & $\begin{array}{l}\text { Aumentar relações de intermediação entre } \\
\text { as pessoas que precisam de ajuda e as } \\
\text { pessoas que podem oferecer ajudar, } \\
\text { construir relacionamentos. A forma de } \\
\text { conectar também é importante, tanto } \\
\text { pessoal quanto através de ferramentas e } \\
\text { mídias sociais. }\end{array}$ & $\begin{array}{l}\text { O contato entre os membros da comunidade } \\
\text { foi realizado tanto virtual como } \\
\text { presencialmente. } \\
\text { No entanto, na comunidade virtual no } \\
\text { Facebook® houve uma baixa interação por } \\
\text { parte dos membros, especialmente no que } \\
\text { tange à resolução de problemas. }\end{array}$ \\
\hline Liderança & $\begin{array}{l}\text { Dentro da comunidade podem surgir } \\
\text { maneiras diversas de liderar: através de } \\
\text { redes de trabalho: pensamentos críticos, } \\
\text { pessoas que registrem a prática, pioneiros, } \\
\text { etc. Estas formas de liderar podem estar } \\
\text { centralizadas em um ou dois membros, ou } \\
\text { amplamente distribuídas. As disposições da } \\
\text { liderança mudam conforme a evolução da } \\
\text { comunidade. }\end{array}$ & $\begin{array}{l}\text { Foram escolhidos pelo grupo } 3 \text { líderes } \\
\text { comunitários para representar os interesses } \\
\text { dos membros. Durante o período observado, } \\
\text { no entanto, os líderes não tiveram um papel } \\
\text { central como esperado. Não houve práticas } \\
\text { de integração entre líderes e membros, o que } \\
\text { pode ter contribuído de forma negativa para } \\
\text { que a comunidade digital Facebook® se } \\
\text { tornasse mais integrada e atrativa. }\end{array}$ \\
\hline Membros & $\begin{array}{l}\text { Os membros de uma comunidade devem } \\
\text { participar de forma crítica, porém seu } \\
\text { envolvimento com a comunidade deve ser } \\
\text { difuso. A inclusão de membros pode ser } \\
\text { muito útil na consolidação da legitimidade } \\
\text { da comunidade para si mesmo e na } \\
\text { organização em geral. }\end{array}$ & $\begin{array}{l}\text { Foram identificados diferentes níveis de } \\
\text { participação dos membros, divididos de } \\
\text { acordo com a literatura em: central, ativos e } \\
\text { periféricos. }\end{array}$ \\
\hline
\end{tabular}


Quadro 7 - Elementos de uma comunidade de prática

(conclusão)

\begin{tabular}{|c|c|c|}
\hline $\begin{array}{l}\text { Projetos de } \\
\text { aprendizagem }\end{array}$ & $\begin{array}{l}\text { Comunidades de prática aprofundam seu } \\
\text { compromisso mútuo quando assumem a } \\
\text { responsabilidade por uma agenda de } \\
\text { aprendizagem, o que permite uma prática } \\
\text { regular. As atividades devem ser } \\
\text { direcionadas para explorar conhecimento, } \\
\text { encontrar lacunas, desenvolver projetos de } \\
\text { aprendizagem envolvendo membros com } \\
\text { conhecimentos de áreas diferentes, criar } \\
\text { guias para iniciantes, etc. }\end{array}$ & $\begin{array}{l}\text { O grupo desenvolveu projetos colaborativos } \\
\text { para a participação no evento Mundo } \\
\text { SENAI: casa sustentável; estacionamento } \\
\text { inteligente; braço hidráulico; bicicleta } \\
\text { sustentável. } \\
\text { Durante este período foi observada uma } \\
\text { atividade comunitária um pouco mais intensa } \\
\text { com relação à publicação de pesquisas e } \\
\text { troca de informações para a composição dos } \\
\text { projetos. }\end{array}$ \\
\hline Artefatos & $\begin{array}{l}\text { As comunidades de prática devem produzir } \\
\text { seu próprio conjunto de artefatos: } \\
\text { documentos, ferramentas, histórias, } \\
\text { símbolos, sites, etc. Os artefatos são } \\
\text { representações das práticas exercidas e } \\
\text { devem ser usados como base no processo } \\
\text { de evolução da comunidade. }\end{array}$ & $\begin{array}{l}\text { Foram observados alguns aspectos nas ações } \\
\text { iniciais de criação do grupo (por exemplo: } \\
\text { definição dos objetivos, escolha dos líderes, } \\
\text { customização do espaço, nome e símbolo), } \\
\text { mas que não representam um conjunto de } \\
\text { artefatos significativo para a prática. }\end{array}$ \\
\hline
\end{tabular}

Fonte: dados da pesquisa.

Ao elencar os elementos que constituem um CoP é possível perceber que a comunidade virtual no Facebook ${ }^{\circledR}$ realizou atividades correspondentes em todos os pontos, com maior ou menor intensidade. Porém, devido à baixa interação entre os membros, a comunidade virtual no Facebook® não conseguiu atingir uma construção social plena, o que para Brown e Duguid (1991) acontece quando surge o entendimento compartilhado a respeito de um problema ou situação exposta na comunidade e que promove a união, cria confiança e reciprocidade entre os membros. Como consequência, não constituiu significados conjuntos que fariam com que grupo viesse a se tornar uma CoP de forma efetiva.

Pressupõe-se então que a comunidade virtual criada no Facebook® possa estar evoluindo para tornar-se uma comunidade de prática, pois, cabe destacar, houve um recorte temporal para concluir o estudo. O curto período de tempo para desenvolvimento da comunidade é um fator que pode ter limitado o estabelecimento de relações sociais vinculantes entre os membros.

Um dos pressupostos do estudo era o de que a comunidade virtual no Facebook® pudesse colaborar com o desenvolvimento profissional dos aprendizes, inicialmente por meio de uma aprendizagem social que possibilita a troca de saberes práticos ligados ao desenvolvimento de competências (Le Boterf, 2003; Zarifian, 2001). Nesse sentido, a entrevista final de avaliação junto aos participantes buscou identificar a sua percepção quanto à contribuição dessa vivência para o seu desenvolvimento profissional. Aqui estão alguns relatos: 
Para o meu conhecimento é muito bom, por exemplo, na parte de motores, que mostram como é que se ligam, como se usam. Ainda não estou trabalhando nessa parte da elétrica, mas quando eu trabalhar pode me ajudar muito. (Entrevistado I - Aprendiz)

Porque eu não conseguia me ver dentro de uma empresa, não entendia como seria. Daí eu fui vendo pelo grupo, perguntando, olhando os vídeos e isso foi me ajudando a entender. (Entrevistado B - Aprendiz)

Sim, contribuiu na parte de troca de ideias, serviu para isso. Pessoas postando ali diferentes ideias, sobre diferentes assuntos. Isso sim, daí tu aprende a receber uma informação e debater sobre ela. Nessa parte de debater sim, acho que isso contribuiu. (Entrevistado C Professor)

Me ajudou com coisas que eu não sabia e tinha dificuldades. Eu vi no grupo, fui atrás, pesquisei. Fiz calmamente, sozinho para conseguir entender melhor, prestar mais atenção. Isso me deixou mais experiente, digamos. (Entrevistado $\mathrm{H}-$ Aprendiz)

O estudo também buscou avaliar quais ações realizadas na comunidade contribuíram para a criação de formas de colaboração e ajuda mútua entre os participantes. Esses dois fatores estão relacionados à ideia de Rocha (2000) sobre a construção da emancipação, que se daria a partir da troca de experiências e do convívio em sociedade, comunicação e reconhecimento de símbolos. Nessa lógica, ao exercer suas capacidades e competências, o indivíduo passaria a se perceber como útil. Esse senso de utilidade traz à tona o sentimento de inclusão, de fazer parte de algo maior, permitindo que o indivíduo se torne empoderado ou emancipado para sair da condição social de vulnerabilidade na qual se encontra.

Ao avaliar a colaboração, percebeu-se a amplitude desse sentido quando, de maneira geral, todas as publicações feitas no espaço digital, independentes do seu conteúdo ou origem, foram postadas com a finalidade de compartilhar algum tipo de informação ou conhecimento, e, nesse sentido, de colaborar. Identificaram-se algumas iniciativas de apoio e encorajamento, 
ações que envolveram desde pedidos de ajuda para esclarecer dúvidas, a união através de trabalhos feitos em equipe e projetos colaborativos, publicação motivacionais, entre outras. Essas atividades integraram os participantes e deram início ao processo de seu reconhecimento como seres comunitários, pertencentes a uma iniciativa maior, sentimentos que são destacados por Gaiger (2004) na criação dos laços sociais vinculantes, importantes para a união do ser à coletividade, onde este se perceber como membro integrado e seguidor de determinados princípios e capacitado para apresentar suas contribuições dentro do grupo.

Essas percepções foram destacadas por alguns participantes nas entrevistas finais de avaliação, que apontam o despertar de sensos como ajuda mútua, utilidade para com o grupo e confiança entre os membros:

Eu me senti ajudando as pessoas. É que um ajuda o outro na realidade nesse grupo né, daí um tem dificuldade em fazer uma coisa que eu sei daí eu vou ali e ajudo ele né, e quando eu tenho dificuldade e eles me ajudam, porque não é um ou outro, são vários. Isso daí me auxiliou e eu me senti participante por poder auxiliar os outros com o meu conhecimento. As pessoas me procuraram pedindo ajuda. (Entrevistado B - Aprendiz)

Eu tive ajuda, meu grupo também, ainda mais quando eu precisei de alguma informação ou falar com alguém, com um professor, um colega. Ninguém se negou em me ajudar. (Entrevistado D - Aprendiz)

O pessoal do grupo colaborou muito, quando respondiam as perguntas que a gente fazia, ajudando a gente, dando confiança para dar o número (telefone) para a gente ligar ou mandar Whats mesmo. A gente mandava as nossas dúvidas e eles respondiam. (Entrevistado H- Aprendiz)

É importante perceber que a ajuda mútua entre os participantes não aconteceu somente pelo Facebook®, mas também por outros meios de comunicação (como ligações por telefone e mensagens pela mídia social WhatsApp $\left.{ }^{\circledR}\right)$, além das trocas de informações e ideias presencialmente (face a face) entre os participantes. Contudo, é relevante lembrar que, dentro 
do espaço no Facebook®, apenas uma parte dos membros da comunidade participaram mais ativamente, conforme já foi anteriormente demonstrado; boa parte dos membros demonstrou uma atitude mais passiva, de observação das postagens.

A análise dos depoimentos indica que os participantes perceberam que fazer parte da comunidade digital Facebook ${ }^{\circledR}$ trouxe algumas contribuições para o seu desenvolvimento profissional, pois proporcionou a eles um maior contato com o mercado de trabalho através de publicações, projetos colaborativos que denotam trabalho em equipe, independência para pesquisar e busca de conhecimento para a aprendizagem técnica. Não foram identificadas inclusões produtivas plenas, mas sim algumas iniciativas de apoio e encorajamento relacionadas ao uso do espaço comunitário para a ajuda no esclarecimento de dúvidas, a união através de trabalhos feitos em equipe e projetos.

$\mathrm{Na}$ entrevista final de avaliação, todos os entrevistados, quando questionados a respeito, indicaram interesse em continuar participando da comunidade no Facebook ${ }^{\circledR}$, considerando-a como um canal de ajuda e aprendizado mútuo. Porém, é importante ressaltar que existe um grande desafio com relação à formação de líderes comunitários que atuem no sentido de conduzir e promover a integração entre os membros, tornando a comunidade mais integrada e atrativa. A criação de lideranças ou de comitês de governança é um dos fatores críticos apontados para o sucesso de CoP (WENGER, 2001) e será um desafio para o grupo, já que os líderes eleitos pelo grupo tiveram uma atuação na criação da comunidade em si, mas não assumiram efetivamente um papel de integradores sociais, conforme também foi apontado pelos participantes nas entrevistas finais.

\section{CONSIDERAÇÕES FINAIS}

O estudo demonstrou que, de um ponto de vista tecnológico-instrumental, é possível utilizar a mídia social Facebook® para a criação de uma CoP, já que esta mídia possui estrutura e ferramentas virtuais que permitem a concepção de um ambiente interativo, propício para aprendizagem social advinda do compartilhamento de informações, ideias, práticas e experiências.

Com relação à aprendizagem, identificaram-se, nas práticas comunitárias, alguns processos que possibilitaram uma aprendizagem social entre os membros: trocas de informação, participação em eventos, projetos colaborativos, compartilhamentos, etc. Esses fatores denotam a possibilidade de trabalho em equipe, independência para pesquisar e buscar

REAd | Porto Alegre - Vol. 23 - No Especial - Dezembro 2017 - p. 93-125 
o conhecimento relacionado à aprendizagem profissional. Porém, a participação ocorreu de forma mais ativa apenas por um grupo central (como é característico nas CoP) e o nível de interação entre os participantes poderia ter sido bem mais expressivo.

Ainda que de maneira limitada, a comunidade virtual no Facebook® conseguiu contribuir com o desenvolvimento profissional dos membros quando propiciou formas de aprendizagem informal nas áreas de seu domínio técnico, principalmente com relação a aspectos de postura e comportamento, trabalho em equipe e compartilhamento de ideias. Esses elementos contribuem para o empoderamento dos indivíduos como a criação de autonomia, liberdade, independência e senso de pertencimento. Realizaram-se algumas práticas onde foram observadas formas de ajuda mútua e cooperação, iniciativas de apoio e encorajamento representadas por projetos colaborativos, ajuda para esclarecer dúvidas, trabalhos feitos em equipe, publicações motivacionais, etc. Através do espaço virtual foram estabelecidos vínculos sociais que futuramente, podem vir a colaborar para superar as condições de vulnerabilidade em que o grupo se encontra.

No entanto, o elemento considerado chave para o desenvolvimento de uma CoP é a interação (WENGER et al., 2002) e esta apresentou um nível baixo entre os participantes da pesquisa. Esse obstáculo pode ser atribuído à falta de atuação das lideranças em práticas de integração e a criação de um núcleo comunitário, o que pode ter contribuído para que a comunidade digital Facebook ${ }^{\circledR}$ se tornasse menos integrada e atrativa. A dificuldade de escrita e o vocabulário limitado dos participantes, conforme foi observado, também parecem ter influenciado na baixa interação. Além disso, identificaram-se ações narcisistas entre os membros, como o exibicionismo e comportamento superficial, aspectos descritos em estudos prévios como sendo característicos da mídia social Facebook® (PAPACHARISSI, 2010; CARPENTER 2011; RYAN; XENOS, 2011). Observou-se, por exemplo, que muitas vezes os pedidos de ajuda ocorriam de forma mais bidirecional (por mensagem privada no Facebook® ou por Whatsapp $\left.{ }^{\circledR}\right)$, em detrimento de uma interação mais aberta com toda a comunidade.

O desenvolvimento da união em uma comunidade depende de um alto nível de interação e de ações que estimulem a confiança e a colaboração entre os membros (PROBST e BORZILLO, 2009). Um dos fatores de limitação da pesquisa relaciona-se ao tempo de desenvolvimento da comunidade digital (5 meses), que pode ser considerado curto, tendo em vista que é preciso um tempo considerável de convivência entre os membros para consolidar as relações de confiança, apoio e ajuda mútua que possam ser desenvolvidas. Além disso, formas de inclusão produtiva esperadas para o grupo que apresenta perfil sócio vulnerável não 
foram observadas devido ao recorte temporal da pesquisa.

Como sugestão para estudos futuros pode-se dar continuidade a esta experiência utilizando grupos multiculturais de perfis diferentes, tanto sociais quanto acadêmicos, para que seja possível avaliar o desenvolvimento de CoP em mídias sociais. Além disso, sugere-se criar e analisar o processo de desenvolvimento de comunidades de prática em grupos socialmente vulneráveis utilizando outras mídias sociais, como o WhatsApp®. Pode-se pensar também, em estudos sobre CoP que usem simultaneamente diferentes mídias sociais.

\section{REFERÊNCIAS}

ALLEE, V. Knowledge networks and communities of practice. OD practitioner, v. 32, n. 4, p. 4-13, 2000.

ANTONELLO, C. S.; GODOY, A. S. Aprendizagem organizacional no Brasil. Porto Alegre: Bookman, 2009.

BAVA, S. C. Tecnologia social e desenvolvimento local. Tecnologia social: uma estratégia para o desenvolvimento. Rio de Janeiro: FBB, 2004.

BROWN, J. S.; DUGUID, P. Organizational learning and communities-of-practice: Toward a unified view of working, learning, and innovation. Organization Science, v. 2, n. 1, p. 40-57, 1991.

CARAPIÁ FAGUNDES, N.; FRÓES BURNHAM, T. Discutindo a relação entre espaço e aprendizagem na formação de profissionais de saúde. Interface-Comunicação, Saúde, Educação, v. 9, n. 16, 2005.

CARPENTER, C. J. Narcissism on Facebook: Self-promotional and anti-social behavior. Personality and individual differences, v. 52, n. 4, p. 482-486, 2012.

CASTELLS, M. A Galáxia Internet: reflexões sobre a Internet, negócios e a sociedade. Rio de Janeiro: Zahar, 2003.

CHANLAT, J. Ciências sociais e management: reconciliando o econômico e o social. São Paulo: Atlas, 2000.

CHIZZOTTI, A. Pesquisa em ciências humanas e sociais. São Paulo: Cortez, 2006.

DENG, L.; TAVARES, N. J. From Moodle to Facebook: Exploring students' motivation and experiences in online communities. Computers \& Education, v. 68, p. 167-176, 2013.

DOWNES, S. Learning networks and connective knowledge. Collective intelligence and elearning, v. 20, p. 1-26, 2006.

FREIRE, Paulo. Pedagogia da autonomia: saberes necessários à prática docente. São Paulo: REAd | Porto Alegre - Vol. 23 - No Especial - Dezembro 2017 - p. 93-125 
Paz e Terra, p. 25, 1996.

FRIEDMANN, J. Empowerment: the politics of alternative development. Minesotta: Blackwell, 1992.

GAIGER, L. I. G. Sentidos e experiências da economia solidária no Brasil. Editora da UFRGS, 2004.

HUNG, H; YUEN, S. Educational use of social networking technology in higher education. Teaching in higher education, v. 15, n. 6, p. 703-714, 2010.

JANCZURA, R. Risco ou vulnerabilidade social?. Textos \& Contextos, v. 11, n. 2, p. 301 $308,2012$.

LACERDA, D. P; DRESCH A.; PROENÇA, A.; ANTUNES, J. A. V. Design Science

Research: método de pesquisa para a engenharia de produção. Gestão \& Produção, v. 20, n. 4, p. 741-761, 2013.

KAPLAN, A. M.; HAENLEIN, M. Users of the world, unite! The challenges and opportunities of Social Media. Business Horizons, v. 53, n. 1, p. 59-68, 2010.

KLEBA, M. E.; WENDAUSEN. A. Empoderamento: processo de fortalecimento dos sujeitos nos espaços de participação social e democratização política. Saúde e Sociedade, v.18, n.4, 2009.

KIMBLE, C.; HILDRETH, P. M. Communities of Practice: Going One Step Too Far? Journal of Management Studies, v.43, n.3, 2006.

LAVE, J.; WENGER, E. Situated learning: legitimate peripheral participation. Cambridge, UK: Cambridge University Press. 1991.

LÉVY, P. A inteligência coletiva: por uma antropologia do ciberespaço. São Paulo: Loyola, 2000 .

LE BOTERF, G. Desenvolvendo a competência dos profissionais. Porto Alegre: Bookman, 2003.

MACHADO, L. FREITAS J. C. S., KLEIN, A., SABINO, A Design Research como método de pesquisa de administração: Aplicações práticas e lições aprendidas. Revista de Administração - Faces, v. 14, n. 1, p. 95-116, 2015.

MANCA, S.; RANIERI, M. Is it a tool suitable for learning? A critical review of the literature on Facebook as a technology enhanced learning environment. Journal of Computer Assisted Learning, v. 29, n. 6, p. 487-504, 2013.

MANSON, N. J. Is operations research really research? Orion, v. 22, n. 2, p. 155-180, 2006.

OLIVEIRA, A. R. Marx e a exclusão. Pelotas: Seiva, p. 99-107, 2004.

REAd | Porto Alegre - Vol. 23 - No Especial - Dezembro 2017 - p. 93-125 
PALMA, A.; MATTOS, U. A. O. Contribuiçöes da ciência pós-normal à saúde pública e a questäo da vulnerabilidade social. História Ciência e Saúde, v. 8, n. 3, p. 567-590, 2001. PANCKHURST, R.; MARSH, D. Communities of Practice. Using the Open Web as a Collaborative Learning Platform. In: Proceedings of the iLearning Forum. 2008.

Disponível em: https://hal.archives-ouvertes.fr/hal-00291874/document. Acesso em: 1 mar 2015 .

PAPACHARISSI, Z. A networked self: identity, community, and culture on social network sites. London: Routledge, 2010.

RYAN, T.; XENOS, S. Who uses Facebook? An investigation into the relationship between the Big Five, shyness, narcissism, loneliness, and Facebook usage. Computers in Human Behavior, v. 27, n. 5, p. 1658-1664, 2011.

ROCHA, M. P. A questão cidadania na sociedade da informação. Ciência da Informação, v. 29, n. 1, p. 40-45, 2000.

SANTOS, B. S. Pela mão de Alice: o social e o político na pós-modernidade. São Paulo: Cortez, 1999.

SCHLAGER, M. S.; FUSCO, J. Teacher professional development, technology, and communities of practice: are we putting the cart before the horse? The Information Society, v. 19, n. 3, p. 203-220, 2003.

SOUZA, A. A. N.; SCHNEIDER, H. N. Aprendizagem nas redes sociais: colaboração online na prática de ensino presencial. In: Simpósio Internacional de Educação a Distância e Encontro de Pesquisadores em Educação a Distância. Anais... 2012, 2012.

TAKEDA, H.; VEERKAMP, P.; YOSHIKAWA, H..Modeling design process. AI Magazine, v. 11, n. 4, p. $37,1990$.

TUCKER, V. Facebooking in Distance Education: constructing virtual communities of practice. Proceedings of TCC Worldwide Online Conference. TCCHawaii, Anais... 2012. p. 62-80.

VAISHNAVI, V.; KUECHLER, B. Design Research in Information Systems. Association for Information Systems, v.2, 2004. Disponível em: http://desrist.org/design-research-ininformation-systems. Acesso em: 10 abr de 2014.

WENGER, E. Communities of practice and social learning systems. Organization, v. 7, n. 2, p. 225-246, 2000.

WENGER, E.; MCDERMOTT, R. A.; SNYDER, W. Cultivating communities of practice: a guide to managing knowledge. Cambridge: Harvard Business Press, 2002. 
WENGER, E.; SNYDER, W. M. Comunidades de prática: a fronteira organizacional. Cambridge: Harvard Business Review, 2001.

WENGER, E.; TRAYNER, B.; DE LAAT, M. Promoting and assessing value creation in communities and networks: A conceptual framework. The Netherlands: Ruud de Moor Centrum, Report 2010 - 2011.

ZARIFIAN, P. Objetivo Competência. São Paulo: Atlas, 2001. 